\title{
A DIVERSIDADE DAS GEOGRAFIAS ECONÔMICAS
}

\author{
PAUL CLAVAL \\ Universidade de Paris-IV
}

A edificação da geografia econômica moderna foi uma obra longa e complexa. Ela começou no meio do século XIX, mas antes do seu nascimento existia uma disciplina vizinha, da qual herdou uma parte de suas fontes e de seus objetivos: a estatística. ${ }^{1}$ É importante analisar as diversas perspectivas que coexistiram ou se opuseram nesse domínio. Vamos apresentá-las segundo a ordem em que influenciaram a construção da geografia econômica.

\section{A Geografia Econômica Clássica}

A geografia econômica desenvolveu-se no meio do século XIX, quando o crescimento do comércio internacional acelerou a especialização de cada região na produção em que ela tinha a mais forte vantagem relativa. Essa disciplina, já presente em algumas publicações de Carl Ritter

${ }^{1} \mathrm{O}$ termo estatística foi introduzido no século XVI pelo Italiano Giovanni Botero. O seu objetivo era apresentar uma descrição quantitativa dos países e das suas divisões administrativas. Esta disciplina se desenvolveu no fim do século XVII na Inglaterra sob o nome de aritmética política, com William Petty, e na França, com Vauban. Foi na Alemanha que seu desenvolvimento foi o mais importante no século XVIII sob o nome de ciência cameralista, ilustrada pelos nomes de Conring and Achenwald. Sua influência sobre a ciência econômica foi forte neste país, onde a disciplina foi concebida como uma análise das atividades de um Estado e foi chamada "Economia nacional". No século XIX, todos os países modernos desenvolveram serviços estatísticos, com publicações regulares. A estatística gráfica, que apareceu nos anos trinta desse século, foi a primeira forma da cartografia temática (Palsky, 1996). Os primeiros geógrafos modernos, como Émile Levasseur, estavam conscientes do papel da estatística no desenvolvimento de sua disciplina. A ideia de construir a geografia humana a partir dos mapas de densidades, que tinha um papel central na obra de Vidal de la Blache, vinha da estatística gráfica através de Levasseur. Sobre a história da estatística, v. Levasseur, 1889, p. 50-52; Dockès, 1969, e Lazarsfeld, 1970, p. 79-102. 
(1974[1852]), foi codificada nos anos 1860 pelo geógrafo alemão Karl Andrée (1860-1874) e sistematizada por seu compatriota, Götz (1882). Essa geografia econômica era essencialmente descritiva, oferecendo retratos das áreas de produção e dos fluxos de bens na cena mundial. Ela não falava das atividades econômicas de autoprodução e autoconsumo: só se interessava pela fração da produção que já era comercializada.

Esse tipo de geografia econômica desenvolveu-se rapidamente no Reino Unido e na França nos anos 1880 e 1890 (Chisholm, 1888; Dubois e Kergomard, 1897). Entre as guerras mundiais, ela conheceu um grande sucesso nas universidades dos Estados Unidos onde, em várias ocasiões, era ensinada por geólogos graças à sua competência na estimativa das reservas de carvão, petróleo ou minerais metálicos.

Tal geografia econômica estabelecia relações com a geologia e com a agronomia, mas ignorava completamente a economia - e a economia espacial. Ela prevaleceu até os anos 1950. A sua maior contribuição ao desenvolvimento da geografia econômica foi a análise das condições climáticas, pedológicas ou geológicas da distribuição dos recursos naturais, e a consideração do papel das técnicas nos processos de produção agrícola ou industrial: ela introduziu no domínio da geografia agrícola as noções de agricultura intensiva ou extensiva, ou a distinção entre agricultura comercial e agricultura familiar; no domínio da geografia industrial, ela insistiu sobre a concentração vertical ou horizontal das empresas e sobre a influência dos consórcios: cartels na França, Konzerne na Alemanha, trusts nos Estados Unidos. Enfatizou o papel dos mercados de matérias primas no crescimento da produção e dos fluxos (Maurette, 1921). Desenvolveu a cartografia dos fluxos de bens e da produção e levou a descobrimentos importantes, como, por exemplo, o da concentração das indústrias no Industrial Belt do Nordeste dos Estados Unidos (Geer, 1927).

Essa geografia econômica jogou um papel importante no ensino médio da geografia nos países europeus. Ela oferecia um panorama das atividades econômicas as mais signifícativas no nível mundial: a produção e o comércio internacional de alimentos; a produção e o comércio mundial de matérias-primas minerais; a produção e o comércio mundial de carvão e de petróleo. O panorama insistiu também sobre a produção de energia a partir do carvão, do petróleo, ou da hidreletricidade. Uma apresentação rápida das atividades industriais seguia, com ênfase sobre a siderurgia, e um tratamento mais rápido das indústrias mecânicas e têxteis. Desde os anos trinta, a produção de automóveis era integrada ao panorama. Um pouco mais tarde, com Pierre George, a geografia da energia (George, 1950) e do consumo tornou-se um aspecto significativo da pesquisa. 
No ensino médio, a geografia econômica tinha um duplo papel: ela mostrava o funcionamento da economia comercial mundial, permitia uma classificação dos países e sublinhava o papel dos mais produtivos. Era uma geografia das bases econômicas do poder dos Estados. Na França, o programa da geografia do último ano do ensino secundário se chamava "As grandes potências". Para os jovens dos países já desenvolvidos, foi uma maneira de mostrar o seu papel na cena mundial e também de fortalecer o sentido da identidade nacional.

\section{A Geografia Econômica de inspiração econômica: a influência da Economia Espacial}

O segundo tipo de geografia econômica derivou da economia espacial. Este gênero de abordagem desenvolveu-se essencialmente nos anos cinquenta e sessenta do século XX, mas teve pioneiros desde o século XIX: economistas, como Von Thünen (1826), engenheiros como Launhardt (1888), sociólogos como Alfred Weber (1909). Na primeira metade do século XX, ela foi desenvolvida por economistas como August Lösch $(1938 ; 1940)$, ou geógrafos como Walter Christaller (1934). Ela permanecia até o meio do século uma especialidade da Alemanha e dos países escandinavos, da Suécia, mais particularmente.

Em seguida da descrição do circuito econômico por François Quesnay (1758) e da publicação do livro fundador de Adam Smith (1776), a ciência econômica do fim do século XVIII e do começo do século XIX tornou-se uma economia política, isto é, uma ciência das relações econômicas entre as classes sociais: os proprietários fundiários, os empreendedores e os assalariados. Ela mostrava a competição entre esses grupos na repartição da riqueza nacional e a gênese de relações de exploração.

O nascimento da economia espacial datou do momento em que a economia mudou. Ela deixou de ser uma economia política e tornou-se uma análise dos processos à escala dos indivíduos e das empresas. Os trabalhos de von Thünen jogaram um papel importante nessa mudança.

A fundação teórica da economia espacial não repousava sobre a economia política - foi edificada sobre a análise econômica. Para esta nova maneira de compreender a vida econômica, a sociedade econômica era feita de agentes perfeitamente racionais. Eles desejavam maximizar o seu proveito ou a sua renda, se fossem produtores, e a sua utilidade, se fossem consumidores. Como suas decisões eram racionais, não era necessário 
estudá-las empiricamente. O teórico da economia possuía a capacidade de explicá-las através da análise das possibilidades de lucro, renda ou utilidade oferecidas numa situação dada. As mais importantes variáveis para o economista espacial e para o geógrafo econômico eram as dotações em fator terra e em fator trabalho, bem como o custo da distância para a transferência de bens, pessoas e informações.

O problema era o de explicar a localização das atividades econômicas a partir da análise das escolhas feitas pelos produtores para maximizar seus lucros e, por sua vez, pelos consumidores para maximizar seus usos. No caso em que produtores e consumidores competem pelo uso do mesmo solo - nas áreas urbanas, por exemplo — a solução da questão parecia mais difícil. William Alonso (1964) imaginou uma solução elegante nos anos sessenta graças ao recurso às curvas de lances [enchères].

A geografia econômica desenvolvida nos anos cinquenta e sessenta não tratava somente das escolhas individuais. Ela explorava as consequências coletivas das escolhas de cada um e as suas consequência no funcionamento, no caso dos mercados (a microeconomia), e os mecanismos da circulação da renda, do lucro, do investimento e da poupança (a macroeconomia). As antecipações e a especulação jogam um papel importante na criação de dinheiro e, consequentemente, no dinamismo das economias.

Os geógrafos descobriram a economia espacial nos anos cinquenta através da leitura de três livros, os de Edgar Hoover (1948) e Walter Isard (1956), nos países de língua inglesa, e o de Claude Ponsard (1955), na França. Como para os economistas espaciais, os geógrafos fizeram mais uso da microeconomia do que da macroeconomia. Nos Estados Unidos e na Inglaterra a preocupação da maioria dos pesquisadores foi verificar se os modelos desenvolvidos pelos economistas espaciais explicariam bem a realidade: para tratar as estatísticas que esse trabalho necessitava, eles enfatizavam os métodos quantitativos. Os resultados foram importantes para explicar a localização das produções agrícolas e industriais, mas foram os estudos sobre as cidades e as redes urbanas que se destacaram (Berry e Horton, 1970). A lição essencial da geografia econômica inspirada pela economia espacial era a ênfase sobre o papel da distância e dos custos de transportes e de comunicação nas distribuições geográficas.

A fraqueza da geografia econômica dos anos cinquenta e sessenta resultava das suas fundações teóricas: à economia espacial clássica não 
coube uma análise do progresso econômico: as suas bases empíricas eram frágeis. O progresso econômico resulta da existência de economias de escala (graças à mobilização de formas concentradas de energia e ao uso de máquinas potentes e eficientes) e de economias externas (graças a um acesso mais barato à informação técnica ou às notícias de mercado). As ferramentas teóricas para entender esses fenômenos foram desenvolvidas no fim do século XIX por Alfred Marshall com a ideia de distrito industrial e de economias externas (1890), na primeira metade do século XX no domínio das economias de escalas (Young, 1928) e dos custos de comunicação (Coase, 1937) e nos anos cinquenta e sessenta no domínio das economias externas (Scitovsky, 1954; Davies e Whinston, 1962 e 1964).

A integração dessas noções no terreno da economia espacial - e, consequentemente, da geografia econômica - tardou, o que significou que o papel do progresso técnico não foi realmente entendido por economistas como Samuelson $(1948 ; 1949)$. Dai a pesquisa de um outro tipo de análise espacial, com o tema dos polos de desenvolvimento, imaginado por François Perroux (1955) e sistematizado por Jacques Boudeville (1966) nos anos cinquenta e sessenta.

Foi apenas uma minoria dos geógrafos econômicos que desenvolveram pesquisas sobre o dinamismo territorial, mas eles integraram o tema das economias de escala e externas antes dos economistas - por exemplo Ullman (1980) ou Claval (1968). A integração do progresso econômico na economia espacial, propriamente, demorou até os anos 1990. Ela foi realizada nos Estados Unidos por Krugman e seus alunos (Krugman 1980, 1991; Fujita et al., 1999).

Um outro terreno onde a geografia econômica superava a economia espacial foi o domínio da economia da informação e da comunicação, graças às pesquisas de Gunnar Törnqvist (1968; 1970) sobre o papel dos contatos face a face e de Claval sobre as economias de comutação, uma fonte essencial das economias externas, e o fator-chave no nascimento dos lugares centrais (Claval, 1963, 1977, 1981, 1987; Crague, 2003; Guillaume, 1998)

O comportamento dos agentes era sempre racional? A hipótese foi que cada um tinha a capacidade de conhecer perfeitamente, e sem custo, todos os dados relativos a uma situação. Já no fim dos anos sessenta pesquisadores exploram outros tipos de comportamentos — os dos satisficers, por exemplo, isto é, dos agentes que não ensaiavam maximizar 
os seus proveitos, rendas ou utilidades, mas escolhiam um nível onde atingiam uma satisfação suficiente.

\section{Geografia Econômica e Economia Política}

Quando a economia se estruturou, no século XVIII e no começo do século XIX, ela se chamava economia política e seu alvo era estabelecer como as riquezas foram divididas entre os diferentes grupos econômicos: proprietários fundiários (seja nas zonas de produção agrícola, seja nas zonas urbanas), proprietários dos meios de produção (os capitalistas) e assalariados. O desenvolvimento da economia política levou a dois resultados maiores: (i) a remuneração dos operários estava limitada pela competição entre eles, e fixada ao nível da sobrevivência e da reprodução da mão-de-obra; (ii) como o crescimento demográfico, a parte da renda total que era atribuída aos proprietários fundiários crescia, ao mesmo tempo em que os níveis de lucro diminuíam.

A perspectiva da economia política se desenvolveu mais cedo que a análise econômica, mas ela desapareceu quase totalmente depois de 1840, mesmo para os marxistas. Marx enfatizava o papel do espaço na primeira parte de sua obra, particularmente quando ele analisa a acumulação primitiva, mas no Capital, ele eliminou-o na teoria da reprodução ampliada por que um processo que tinha uma certa duração não poderia aparecer como revolucionário (Lebebvre, 1972; Claval, 1977). O resultado foi que até os anos 1950, a geografia econômica da inspiração marxista não possuía ferramentas intelectuais para tratar do mundo industrializado. Ela só tratava da acumulação primitiva e de sua persistência no imperialismo (Lênin, 1917/1925; Rosa Luxemburgo, 1916/1965).

Nos anos cinquenta, a geografia econômica da inspiração marxista propunha uma outra interpretação do atraso econômico do Terceiro Mundo: a sua tese central era que os países já industrializados impediriam aos países do terceiro mundo o acesso ao processo da industrialização (Amin, 1970; Emmanuel, 1969; Frank, 1970). O desenvolvimento rápido das economias dos países da Ásia de leste e de sudeste nos anos sessenta e setenta destruiu completamente esse tipo de interpretação.

A vontade de desenvolver uma abordagem crítica no domínio das ciências sociais sob o modelo da ciência iluminista do século XVIII afirmava-se nos anos cinquenta e sessenta sob a influência da Escola de sociologia de Frankfurt (Vanderberghe, 1998-1999). Nessa perspectiva, a geografia econômica dos anos sessenta aparecia como conservadora. Daí o 
desenvolvimento, no ambiente revolucionário do fim dos anos sessenta, de uma corrente radical na geografia. Ela tomou rapidamente uma forma marxista (Harvey, 1973), mas os marxistas estavam doravante conscientes da ausência do espaço na segunda parte da obra de Marx (Lefebvre, 1972; Claval, 1977b). Harvey (1982) escolheu dar ao marxismo a base que lhe faltava. Ele focalizou a sua atenção sobre a rigidez ligada às imobilizações do capital (o spatial fix, o arranjo espacial), que conduziu os capitalistas a mudar periodicamente a localização dos seus investimentos.

A ênfase de Harvey mudou no fim dos anos noventa e no começo dos anos dois mil. Ele desenvolveu uma teoria da acumulação por expoliação, que ampliava ao mundo contemporâneo a teoria da acumulação primitiva.

\section{As alter-geografias econômicas, anarquismo, Raubwirtschaft e inspiração antropológica}

Quer clássica (a economia política), quer marginalista (a análise econômica), a economia enfatizava o papel da concorrência na vida econômica. As críticas dessa ideia foram muitas desde o século XIX. Nesse tempo, a maioria delas vinha dos anarquistas. Para eles, a cooperação entre os seres humanos tinha um papel maior que o da competição.

Foram muitos os geógrafos anarquistas no século XIX (Ferretti, 2007): Pietr Kropotkin, Léon Metchnikoff, Elisée Reclus ou Claude Perron. Pietr Kropotkin publicou no começo do século XX um livro sobre Fields, Factories and Workshops (1913). Ele era crítico da exploração brutal da natureza (já uma preocupação ecológica) e das formas extremas da concorrência. Ele enfatizava a importância da ação cooperativa e o papel, na sua difusão, da eletricidade, fator essencial de descentralização. As suas ideias tiveram um sucesso considerável: no tempo da revolução russa de 1917, os marxistas como Lênin não tinham uma doutrina clara da organização do espaço, por que este faltava nos escritos de Marx. Lênin propunha uma fórmula para resumir a revolução bolchevista: "O que é o comunismo? São os Sovietes nas usinas e a eletricidade no campo!”. A segunda parte desta fórmula vinha de Kropotkin (Claval, 1996). As ideias de Elisée Reclus sobre o papel da cooperação na reforma da economia eram próximas dessas de Pietr Kropotkin.

No começo do século XX, uma outra forma de alter-geografia apareceu na Alemanha: Friedrichs foi o primeiro geógrafo a inquietar-se sobre o problema dos recursos e de sua exploração abusiva. Ele falava de 
Raubwirtschaft (Friedrichs, 1904): foi o precursor das geografias econômicas baseadas sobre a ecologia.

A fonte a mais importante das alter-geografias econômicas foi, todavia, a antropologia econômica. Para os antropólogos, o domínio econômico não se confunde com o das decisões racionais no sentido da maximização dos lucros, da renda ou da utilidade. Para eles, a antropologia econômica estuda a produção de todos os bens materiais e de todos os serviços indispensáveis à vida dos grupos humanos. A procura social tem suas raízes na biologia (alimentação) e na esfera simbólica (consumo ostentatório de riquezas).

A circulação mercantil não parece central nessa perspectiva: as situações de autarquia têm um papel tão importante quanto o da produção comercial. A ênfase não se situa no mercado. Alexei Chayanov (1966), um russo que foi vitima dos expurgos de Stálin, destacou o papel da autoprodução e do autoconsumo dos camponeses.

Para a maioria dos antropólogos, a economia também repousava sobre outras formas de circulação, quer seja a redistribuição, quer seja o dom e o contra-dom. A inspiração vem de Marcel Mauss (1922/1923) e Karl Polanyi (1944). Os geógrafos alter-economistas apoiam-se sobretudo sobre a economia do dom (Caillé, 2000).

Esta leitura de economia impõe-se no estudo das sociedades tradicionais, onde sempre existe uma parte importante de autarquia e onde uma parte importante do consumo é simbólico. Esse tipo de abordagem parece também significativo para entender as sociedades modernas: uma parte importante dos agentes não se conforma ao modelo da escolha racional da teoria econômica; a dimensão simbólica de uma parte do consumo é notória. Portanto, não se pode construir uma geografia econômica moderna sem aceitar algumas das orientações exploradas pela antropologia econômica .

Com a virada cultural da geografia humana, nos anos noventa do século XX, a influência da antropologia econômica tornou-se mais forte na geografia econômica.

\section{Conclusão}

A geografia econômica foi edificada num longo período de tempo. O seu desenvolvimento durou mais de um século e meio e combinou em proporções diversas influências que tinham varias origens. A geografia 
econômica atual combina essas abordagens : o desenvolvimento desde há trinta anos dos estudos sobre a economia da informação e da comunicação, os distritos industriais e a economia do conhecimento oferecem um bom exemplo dessas convergências.

À parte a análise descritiva, sob o modelo da geografia econômica clássica, qual a contribuição principal da disciplina ao entendimento do mundo? A revelação de processos econômico-espaciais explica a distribuição das atividades e dos fluxos econômicos: por exemplo, o papel de zonas de pequenas ou médias empresas, que mostravam um dinamismo excepcional na "Terceira Itália" (Itália do Centro e do Nordeste) nos anos 1970 (Bagnasco, 1977). Para interpretar esse resultado, a análise dos distritos industriais proposta por Alfred Marshall (1890) aparecia como o quadro mais adequado. Mas o problema foi explicar por que esse tipo de distrito, que tinha um papel importante na Inglaterra do fim do século XIX, tinha desaparecido na primeira metade do século vinte. Combinando a economia liberal e a economia marxista, a teoria da regulação de Aglietta (1976) oferecia uma interpretação interessante: o capitalismo clássico do fim do século XIX foi substituído pelo capitalismo fordista das grandes empresas. Hoje este é substituído por uma nova forma de acumulação, o capitalismo flexível, ligado à globalização (Piore e Sabel, 1984). Esse tipo de interpretação mistura a abordagem descritiva da geografia econômica clássica com a abordagem liberal da nova geografia econômica dos anos sessenta, e as preocupações críticas da geografia política misturam-se com a ênfase da alter-economia sobre as formas de cooperação que dão aos distritos industriais a sua vantagem - um ponto caro à alter-economia. Os modelos modernos de distritos industriais (Beccatini, 1991; Scott e Storper, 1986) fazem empréstimos a todas as formas da geografia econômica.

Os problemas da geografia econômica hoje refletem os problemas da própria ciência econômica. No tempo das Luzes, ela era baseada sobre a convicção de que, para melhorar a sociedade, era necessário apenas mostrar as suas contradições: a ciência social era crítica.

As formas de análise científica que se desenvolveram desde os anos 1830 ou 1840 não tiveram o mesmo objetivo. Elas enfatizavam o papel dos mecanismos econômicos na escala do indivíduo e da empresa. Explicavam o mundo econômico, mas sem denunciar as suas injustiças sociais.

No século XX, a escola de sociologia de Frankfurt reintroduziu a ideia de uma ciência crítica. Dai o sucesso dos modelos da economia política e da antropologia econômica: é bom buscar abordagens mais 
sensíveis às desigualdades sociais. O problema é que os modelos usados para analisá-las não se aplicam bem às sociedades contemporâneas. Precisa-se de um conhecimento mais preciso das mecanismos espaciais atuais.

\section{A DIVERSIDADE DAS GEOGRAFIAS ECONÔMICAS}

Resumo: Este artigo focaliza as múltiplas transformações da Geografia Econômica, desde sua perspectiva clássica até as "alter-geografias" inspiradas no anarquismo e na antropologia econômica, passando pelas influências da economia espacial e da economia política.

Palavras-chave: Geografia Econômica, Espaço, Economia

\section{THE DIVERSITY OF ECONOMIC GEOGRAPHIES}

Abstract: This paper focus on multiple transformations in Economic Geography, from classic approaches to "alter-geographies" animated by anarchism and economic anthropology, in addition to other approaches influenced by spatial economy and political economy.

Keywords: Economic Geography, Space, Economy

\section{BIBLIOGRAFIA}

AGLIETTA, M. (1976). Régulation et crises du capitalisme, Paris : Calmann-Lévy.

ALONSO, W. (1964). Location and Land Use : toward a General Theory of Land Rent, Cambridge : Harvard University Press.

AMIN, S. (1970). L'Accumulation à l'échelle mondiale, Paris : Anthropos. ANDREE, K. (1861-1874). Geographie des Welthandels mit geschichtlichen Erlaüterungen, Stuttgart, 2 vol.

BAGNASCO, A. (1977). Tre Italia. La problematica territoriale dello sviluppo italiano, Bolonha : Il Mulino.

BECATTINI, G. (1991). Modeli locali de sviluppo, Milão : Il Mulino. BERRY, B. J. L.; HORTON, F. E. 1970, Geographic Perspectives on Urban Systems, Englewood Cliffs : Prentice-Hall.

BOUDEVILLE, J.-R. (1966). Problems of Regional Economic Planning, Edimburgo : Edinburgh University Press. 
CAILlE, A. (2000). Anthropologie du don : le tiers paradigme, Paris : Desclée de Brouwer.

CHAYANOV, A. V. (1966). On the Theory of Peasant Economy, Nova York : R. D. Irwin.

CHISHOLM, G. (1989). Handbook of Commercial Geography, Londres : Longman.

CHRISTALLER, W. (1933). Die zentralen Orte in Süddeutschland, Iéna, G. Fischer; trad. ing., Central Places in Southern Germany, Englewood Cliffs : Prentice-Hall, 1966.

CLAVAL, P. (1963). Géographie générale des marchés, Paris : Les Belles Lettres.

. (1968). Régions, nations, grands espaces. Géographie générale des espaces territoriaux, Paris : M.-Th. Genin.

. (1977a). "Les réseaux de circulation et l'organisation de l'espace : les fondements théoriques de la région polarisée", p. 355-364 de : Transports et voies de communication, Colloque de Dijon, 14-15 mars 1976, Dijon : Association Universitaire de l'Est.

(1977b). "Le marxisme et l'espace", L'Espace Géographique, $\overline{\text { vol. } 6, \mathrm{n}^{\circ}}$ 3, abril 1977, p. 145-154.

. (1981). La Logique des villes. Introduction à l'urbanologie, Paris : Librairies Techniques.

. (1987). "La métropolisation de l'économie et de la société nordaméricaine", Historiens et Géographes, n 312, dez. 1986-jan. 1987, p. 447-460.

. (1996). "Technical Changes and Contemporary Growth of the Big Metropolis", European Review, Interdisciplinary Journal of the Academia Europaea, vol. 4, n 3, jul., p. 183-191.

COASE, R. H. (1937). "The nature of the firm", Economica, vol. 4, n 16, p. 386-405.

CRAGUE, G. (2004). "Commutation. Essai sur l'économie de l'agglomération", Géographie, Economie, Societé, vol. 6, n 1, p. 9-21.

DAVIES, O. A. e Whinston, A. (1962). "Externalities, welfare and the theory of games", Journal of Political Economy, vol. 70, p. 241-262.

(1964), "The economics of complex systems: the case of municipal zoning", Kyklos, vol. 27, p. 419-446.

Dockès, P. (1969). L’Espace dans la pensée économique du XVIe au XVIIIe siècle, Paris : Flammarion. 
DUBOIS, M.; KERGOMARD, J.-G. (1897). Précis de géographie économique, Paris : Masson.

EMMANUEL, A. (1969). L'Echange inégal, Paris : Maspéro.

FERRETTI, F. (2007). Il Mondo senza la mappa. Elisée Reclus e $i$ geografi anarchici, Milão : Zero in condotta.

FRANK, G. (1970). Le Développement inégal, Paris : François Maspéro.

FRIEDRICH, E. (1904). "Wesen un geographisches Verbreitung der Raubwirtschaft", Pettermann's Mitteilungen, $\mathrm{n}^{\circ} 3$, p. 68-79 e n 4, p. 9295.

FUJITA, M., Krugman, P. e VENABLES, A. J. (1999). The Spatial Economy. Cities, Regions and International Trade, Cambridge: The M.I.T. Press.

GEER, S. de, (1927). "The American manufacturing belt", Geografiska Annaler, vol. 9, p. 233-259.

GENEAU de Lamarlière, I. e STASZAK, J.-F. (2000). Principes de géographie économique. Paris : Bréal.

GEORGE, P. (1950). Géographie de l'énergie, Paris: Marie-Thérèse Genin.

GÖTZ,W. (1882). "Die Aufgabe der 'wirtschaftlichen Geographie (Handelsgeographie)", Zeitschrift der Gesellschaft zur Erdkunde zu Berlin, vol. 17, p. 354-388.

GUILLAUME, M. (1997). "Articulation entre les échanges immatériels : présentation", in A. Obadia (ed.). Entreprendre la ville. Nouvelles temporalités, nouveaux services, La Tour d'Aigues : Editions de l'Aube, p. 229-233.

HARVEY, D. (1982). The Limits to Capital, Oxford : Blackwell.

HIGgINS, B. (1959). Economic Development. Principles, Problems and Policies, Nova York : Norton.

HOOVER, E. M. (1948). The Location of Economic Activity, Nova York : John Wiley, e Cambridge (Mas.) : The M.I.T. Press.

ISARD, W. (1956). Location and Space Economy, Nova York e Cambridge : John Wiley and MIT Press.

KROPOTKIN, P. (1913). Fields, Factories and Workshops, Londres: Benjamin Bloom.

KRUGMAN, P. R. (1980). "Scale economics, product differenciation and the pattern of trade", American Economic Review, vol. 70, p. 950-959. 
(1991). "Increasing returns and economic geography", Journal of Political Economy, vol. 99, p 483-499.

LAUNHARDT, W. (1882). "Die Bestimmung der zweckmassigsten Standortes einer gewerblichen Anlage", Zeitschrift des Vereins Deutscher Ingenieure, vol. 26, p. 106-115.

LAZARSFELD, P. (1970). "Note sur l'histoire de la quantification dans les sciences sociales. La période préparatoire" p. 79-102 de Philosophie des sciences sociales, Paris : Gallimard.

LEFEBVRE, H. (1972). Le Marxisme et la ville, Paris :Calmann-Lévy.

LENIN, V. 1925 (1917). L'Impérialisme, stade suprême du capitalisme, Petrogrado ; trad. fr, Paris.

LEVASSEUR, E. (1889). La Population française, Paris : Rousseau.

LÖSCH, A. (1938). "Beitrage zur Standort Theorie", Schmollers Jb Gesetzgebg. Verw. Volksw., vol 62, p 329-335.

. 1940. Die raümliche Ordnung der Wirstschaft, Jena : G. Fischer.

LUXEMBURGO, R. 1967 (1913), Die Akkumulation des Kapitals, Berlin ; trad. fr, Paris : Maspéro, 1967, 2 vol.

MARSHALL, A. (1890). Principles of Economies, Londres : Macmillan.

MAURETTE, F. (1921). Les Grands Marchés de matières premières, Paris : A. Colin.

MEIER, R. (1965). A Communication Theory of Urban Growth, Cambridge (Mass.) : The M.I.T. Press.

OHLIN, B. (1933). Interregional and International Trade, Cambridge: Harvard University Press.

PASKY, G. (1996). Des Chiffres et des cartes. La cartographie quantitative au XIX $X^{e}$ siècle, Paris : CTHS.

PERROUX, F. (1955). "La notion de pôle de croissance", Economie appliquée, vol. 8, p. 307 sqq. Retomada nas p. 142-144 de F. Perroux, 1961, L'Economie du XXe siècle, Paris : PUF.

PIORE, M. J. e SABEL, C.F. (1984). The Second Industrial Divide. Possibilities for Prosperity, Nova York: Basic Books.

PONSARD, C. (1955). Economie et espace, Paris : SEDES.

$\overline{\text { Armand }}$ Colin.

(1958). Histoire des théories économiques spatiales, Paris:

RICARDO, D. (1817), The Principles of Political Economy and Taxation, Londres. 
RITTER, C. (1974 [1852]), Introduction à la géographie générale comparée, Paris : les Belles Lettres ; ed. or. alemã. Berlim.

QUESNAY, F. (1758). Le Tableau économique, Paris.

SAMUELSON, P. (1948). "International trade and the equalization of factor prices", Economic Journal. vol. 58, p. 163-184.

P. (1949). "International factor-price equalization once again". Economic Journal, vol. 59, p. 181-197.

SCITOVSKY, T. (1954). "Two concepts of external economies", Journal of Political Economy, vol. 62, p. 143-151.

SCOTT, A. J. e STORPER, M. (orgs.) (1986). Production, Work, Territory. The Geographical Anatomy of Industrial Capitalism, Boston: Allen and Unwin.

SMITH, A. (1776). The Wealth of Nations. Londres: W. Strahan and T. Cadell

THRIFT, N. J. (1983). "On the determination of social action in space and time", Environment and Planning D - Society and Space, vol. 1, p. 23-58. TÖRNQVIST, G. (1968). Flows of Information and the Location of Economic Activitives, Lund : Gleerup.

$\overline{\text { Glerrup. }}$ . (1970). Contact Systems and Regional Development, Lund:

ULLMAN, E. L. (1958). "Regional development and the geography of concentration", Papers and Proceedings of the Regional Science Association, vol. 4, p. 179-198.

WEBER, A. (1909). Uber den Standort der Industrien, Tübingen.

WILLIAMSON, O. E. (1975). Markets and Hierarchies, New York: The Free Press.

YOUNG, A. (1928). "Increasing returns and economic progress", Economic Journal, vol. 38, p. 527-542. 